\title{
DAMPAK MODEL PEMBELAJARAN AUDITORY, INTELLEKTUALY, REPATITION (AIR) TERHADAP MINAT BELAJAR SISWA
}

\author{
Reza Miftah Rizkiardi ${ }^{* *}$, Bambang Subali ${ }^{2}$ \\ 1rezamiftahrizkiardi@gmail.com, ${ }^{2}$ bambangfisika@gmail.unnes.ac.id \\ ${ }^{1}$ SD Negeri 02 Banjaran Kecamatan Taman, \\ ${ }^{2}$ Prodi Pendidikan Dasar Pascasarjana Universitas Negeri Semarang
}

\begin{abstract}
ABSTRAK
Tujuan dalam penelitian ini adalah untuk mengetahui adanya dampak model pembelajaran Auditory, Intellektualy, Repatition (AIR) pada minat belajar mata pelajaran IPA dikelas III SDN 02 Banjaran. Latar belakang penelitian ini dilakukan untuk melihat apakah ada dampak dan perubahan minat belajar siswa mata pelajaran IPA di kelas III SDN 02 Banjaran ketika guru menggunakan model pembelajaran Auditory, Intellektualy, Repatition (AIR). Jenis penelitian ini adalah penelitian kualitatif deskriptif. Metode penelitian yang digunakan adalah metode survey, teknik yang digunakan adalah wawancara dan observasi. Hasil penelitian berdasarkan wawancara dan observasi terhadap guru dan siswa menunjukan adanya dampak perubahan minat belajar mata pelajaran IPA materi cuaca dan pengaruhnya terhadap siswa kelas III SDN 02 Banjaran saat guru dalam pembelajaran menggunakan model pembelajaran Auditory, Intellektualy, Repatition (AIR) .
\end{abstract}

Kata kunci: Dampak,Model Auditory, Intellektualy, Repatition (AIR), Minat Belajar

\section{PENDAHULUAN}

Pendidikan merupan kegiatan belajar mengajar yang diberikan guru kepada siswanya agar dapat dibimbing dan memperoleh pengetahuan luas yang siswa belum tahu menjadi tahu untuk menciptakan manusia yang berkualitas guna mencapai cita-cita yang diharapkan. Pendidikan disekolah dasar merupakan lembaga yang dikelola pemerintah yang dimana terdiri dari kelas 1 sampai kelas 6, pendidikan di sekolah dasar berbeda dengan pendidikan lainnya karena di sekolah dasar mata pelajaran yang dilakukan dijadikan satu pembelajaran seperti mata pelajaran IPA dan IPS yang menjadi satu kesatuan tidak terpisah seperti di SMP maupun SMA.

Model pembelajaran menurut Afandi, dkk (2013:16) yaitu suatu pedoman yang direncanakan dimana didalamnya terdapat strategi, teknik, dan metode untuk mencapai tujuan pembelajaran yang diinginkan. Perlu diketahui bahwa model-model pembelajaran yang dapat digunakan ketika pembelajaran sangat banyak 
macam dan bentuknya, namun dalam penelitian ini memfokuskan mengambil model pembelajaran yang berbntuk diskusi dan berargumentasi memecahkan masalah seperti model pembelajaran Auditory, Intellectualy, Repatition (AIR), menurut Shoimin (2014:29) Auditory, Intellectualy, Repatitionmemiliki definisi masingmasing yang dapat dijelaskan sebagai berikut : Auditory merupakan belajar haruslah dengan mengakses kata dan bunyi, dengan cara berdiskusi dengan orang lain, berpersentasI, memberikan tanggapan dari ide dan gagasannya. Intellectually diartikan bahwa belajar harus dilakukan dengan berpikir dalam konsep, memecahkan suatu masalah, dan mengidentifikasinya. Repatition diartikan sebagai pengulangan dalam belajar agar lebih memahami suatu konsep pembelajaran yang dilakukan.

Menurut Susanto (2013:170) pembelajaran IPA merupakan pembelajaran yang dilakukan melalui proses untuk menumbuhkan suatu sikap ilmiah dari siswa akan pemahamnnya terhadap IPA. Oleh karena itu pembelajaran IPA yang dilakukan di sekolah dasar haruslah sesuai dengan pembelajaran yang sederhana melalui pengamatan, berdiskusi, saling berpendapat satu dengan lainnya, sehingga tidak dilakukan hanya hafalan-hafalan materi semata. Dengan demikian siswa akan memahami, mengerti dan mampu mengembangkan ide gagasannya mengenai materi yang diajarkan. Hal tersebut membuat minat belajar siswa terhadap mata pelajaran IPA harus lebih dikembangkan. Minat memiliki pengaruh yang besar terhadap pembelajaran. Jika menyukai suatu mata pelajaran, siswa akan belajar dengan senang hati tanpa rasa beban. Minat belajar yang telah dimiliki siswa merupakan salah satu faktor yang dapat memengaruhi hasil belajarnya. Apabila seseorang mempunyai minat yang tinggi terhadap sesuatu, maka akan terus berusaha untuk melakukan sehingga apa yang diinginkannya dapat tercapai (Hamdani, 2011:141).

Pendidikan IPA diharapkan dapat menjadi wahana bagi peserta didik untuk mempelajari diri sendiri dan alam sekitar, serta prospek pengembangan lebih lanjut dalam menerapkannya di dalam kehidupan sehari-hari. Proses pembelajarannya menekankan pada pemberian 
pengalaman langsung untuk mengembangkan kompetensi agar menjelajahi dan memahami alam sekitar secara ilmiah (BSNP, 2006:161). Minat belajar siswa kelas III mata pelajaran IPA di kelas III SD N 02 Banjaran masih sangat rendah.

Faktor yang menyebabkan rendahnya minat belajar siswa berasal dari guru maupun siswa itu sendiri. Adapun faktor dari guru yaitu banyak menggunakan metode ceramah saat pembelajaran. Hal itu dapat menjadikan ketidaksesuain antara materi yang diajarkan dengan metode atau model pembelajaran yang digunakan guru. Metode ceramah dikatakan kurang menumbuhkan minat belajar siswa karena tidak mengajak siswa untuk aktif dalam pembelajaran, dan tidak menyampaikan hal-hal yang dapat menyenangkan siswa dalam pembelajaran sedangkan faktor dari siswa yaitu siswa bermain sendiri, berbicara dengan teman-temannya saat diberikan pelajaran, tidak fokus mengikuti pelajaran, dan jika diberikan pertanyaan cenderung tidak aktif dalam menjawab pertanyaan dari guru.

Model pembelajaran merupakan suatu cara atau desain ilmiah yang diperunutukan untuk guru dalam melaksankan kegiatan pembelajaran. Dengan adanya model pembelajaran guru sebagai pelaksana pengajaran akan mendapatkan bekal dalam mengajar peserta didik. Model pembelajaran sering kali menjadi alternatif guru dalam penyampaian pembelajaran sehingga dengan penggunaan model pembelajaran saat kegiatan belajar mengajar model pembelajaran bisa menjadi cara efektif menangani kejenuhan peserta didik akan metode ceramah yang kerap kali dilakukan guru pada umumnya.Adapun materi pembelajaran IPA yang dilakukan dalam penelitian adalah mengenai materi cuaca dan pengaruhnya, sesuai dengan Standar Kompetensi, Kompetensi Dasar dan indikator pembelajaran yang akan digunakan di kelas III. Menurut Rositawaty (2008:122-125) pengertian cuaca adalah keadaan udara disuatu tempat tertentu. Hubungan keadaan langit dan cuaca, proses terjadinya hujan, bentuk-bentuk awan dan pengaruh cuaca terhadap kehidupan makhluk hidup.

Dari uraian permasalahan diatas, penulis mengadakan penelitian 
dengan judul "Dampak Model Pembelajaran Auditory, Intellektualy, Repatition (AIR) terhadap minat belajar siswa". Tujuan penelitian ini untuk mengetahui apakah ada dampak perubahan penggunaan model pembelajaran Auditory, Intellektualy, Repatition (AIR) yang dilakukan guru dalam mengupayakan serta menumbuhkan minat belajar siswa kelas III SD N 02 Banjaran pada mata pelajaran IPA materi cuaca dan pengaruhnya.

Berdasarkan teori dan kerangka diatas diajukan hipotesis tindakan "Apakah ada dampak perubahan minat belajar siswa ketika menerima pelajaran dengan model pembelajaran Auditory, Intellektualy, Repatition (AIR) yang dilakukan guru dikelas III SD N 02 Banjaran.

\section{METODE PENELITIAN}

Jenis penelitian ini yang digunakan dalam penelitian ini yaitu penelitian kualitatif deskriptif. Metode penelitianya adalah metode survey. Teknik yang digunakan adalah wawancara dan observasi. Penelitian ini dilaksanakan dalam 2 kali survey observasi atau pengamatan. SD Negeri
02 Banjaran mempunyai 6 rombongan belajar. Dalam penelitian ini fokus peneliti dalam subjek penelitian ada pada kelas III. Jumlah keseluruhan siswa kelas III ada 36 terdiri dari 16 siswa laki-laki dan 20 siswa perempuan. Subyek pelaksana tindakan yaitu guru bernama Agus Budi Raharjo, S.Pd. objek penelitian ini adalah minat belajar siswa dalam penggunaan model pembelajaran Auditory, Intellektualy, Repatition (AIR) dikelas III SD N 02 Banjaran Semester I tahun ajaran 2017/2018 kecamatan taman kabupaten pemalang.

Teknik pengumpulan data dalam penelitian ini adalah wawancara dan observasi (pengamatan). Pada teknik dan tahap ini peneliti akan mendeskripsikan hasil penelitianya berdasarkan hasil wawancara dengan guru, wawancara dengan siswa dan deskripsi hasil pengamatan terhadap guru dan siswa saat pembelajaran menggunakan model pembelajaran Auditory, Intellektualy, Repatition (AIR). 


\section{HASIL DAN PEMBAHASAN}

\section{Hasil Wawancara Guru}

Hasil deskripsi wawancara antara peneliti dan guru sebelum pelaksanaan model pembelajaran Auditory, Intellektualy, Repatition (AIR) pertanyaan pertama dari peneliti yaitu mengenai menggunakan apakah metode/model pembelajaran yang biasa digunakan guru kelas III SDN Banjaran 02 dan apakah sudah berjalan efektif dalam melihat dampak minat belajar siswa, jika tidak model apa yang seharusnya dapat memberikan dampak minat beljar siswa. Lalu pertanyaan kedua yaitu mengenai adakah dampak atau perubahan dari minat belajar siswa ketika guru menerapkan pembelajaran Auditory, Intellektualy, Repatition (AIR) dibanding menggunakan metode pembelajaran ceramah.

Lalu setelah peneliti melontarkan 2 pertanyaan kunci ke subyek pelaksana penelitian yaitu guru kelas III SDN
Banjaran 02 Bapak Agus Budi Raharjo, S.Pd maka guru kelas dapat menjawab bahwa untuk metode atau model pembelajaran yang biasa dilakukan pada umumnya yaitu menggunakan metode ceramah. Metode ceramah berdasarkan jawaban dari guru kelas memang terlihat kurang efektif dalam melihat dampak minat belajar siswa, guru kelas menyadari akan kondisi tersebut.

Maka dari itulah subyek pelaksana tindakan yakni guru berupaya menggunakan metode/model pembelajaran lain agar dampak minat belajar siswa kelas III mapel IPA SDN Banjaran 02 dapat dikembangkan. Kemudian dari pada itu guru akan menggunakan model pembelajaran Auditory, Intellektualy, Repatition (AIR) dalam upaya mengetahui dampak minat belajar siswa pada mata pelajaran IPA.lebih jelasnya perhatikan tabel berikut 
Tabel 1. Rekapitulasi Hasil Wawancara dengan Guru

\begin{tabular}{|c|c|c|c|}
\hline No & Pertanyaan & Jawaban & Kesimpulan \\
\hline 1. & $\begin{array}{l}\text { Menggunakan metode/model apakah } \\
\text { disaat pembelajaran dikelas III? Apa } \\
\text { sudah efektif dalam menumbuhkan } \\
\text { minat belajar? Jika tidak model } \\
\text { pembelajaran apa yang tepat? }\end{array}$ & $\begin{array}{l}\text { Biasanya metode } \\
\text { ceramah. Untuk } \\
\text { menumbuhkan } \\
\text { minat belajar perlu } \\
\text { dicoba model AIR }\end{array}$ & $\begin{array}{l}\text { Proses peralihan } \\
\text { metode ceramah ke } \\
\text { model AIR }\end{array}$ \\
\hline 2. & $\begin{array}{l}\text { Adakah dampak perubahan dari } \\
\text { penerapan model pembelajaran } \\
\text { Auditory, Intellektualy, Repatition } \\
(\text { AIR) }\end{array}$ & $\begin{array}{l}\text { Ada karena dengan } \\
\text { model Auditory, } \\
\text { Intellektualy, } \\
\text { Repatition (AIR) } \\
\text { siswa terlihat } \\
\text { mengantuk, antusias } \\
\text { aktif dan tentu saja } \\
\text { minat belajar siswa } \\
\text { tinggi. }\end{array}$ & $\begin{array}{l}\text { Sudah ada dampak } \\
\text { bahwa siswa minat } \\
\text { belajarnya tumbuh } \\
\text { ketika guru } \\
\text { menggunakan } \\
\text { model Auditory, } \\
\text { Intellektualy, } \\
\text { Repatition (AIR) }\end{array}$ \\
\hline
\end{tabular}

\section{Hasil Wawancara Siswa}

Hasil deskripsi wawancara terhadap salah satu siswa kelas III SDN Banjaran 02 sebelum dan sesudah pelaksanaan pembelajaran menggunakan model pembelajaran Auditory, Intellektualy, Repatition (AIR) menghasilkan bahwa subjek siswa yang sedang di wawancara bernama Muhammad Syahril. Peneliti menanyakan beberapa pertanyaan kepada siswa tersebut diantaranya yaitu bagaimana rasanya pembelajaran menggunakan metode ceramah dan model pembelajaran Auditory,
Intellektualy, Repatition (AIR) yang telah dilakukan guru. Selain itu pertanyaan lain juga diberikan peneliti untuk siswa mengenai lebih minat belajar IPA mana dengan menggunakan pembelajaran metode ceramah atau model pembelajaran Auditory, Intellektualy, Repatition (AIR). Setelah peneliti melakukan beberapa pertanyaan kepada siswa maka siswa tersebut menjawab bahwa siswa merasa bahwapembelajaran model pembelajaran Auditory, Intellektualy, Repatition (AIR) dirasakan lebih 
menarik untuk dibelajarkan dari pada metode ceramah yang hanya mengandalkan guru transfer ilmu terhdapap murid saja. Selain itu jawaban siswa terkait minat belajar adalah siswa lebih semangat ketika guru kelas menggunakan model pembelajaran Auditory, Intellektualy, Repatition (AIR) hal itu ditengarai karena dampak pengunaan model pembelajaran Auditory, Intellektualy, Repatition (AIR). Hal tersebut dirasa berbeda dengan kondisi sebelumnya yang siswa mengatakan bahwa ketika guru menggunakan metode ceramah siswa kurang antusias atau bosan serta siswa ada yang mengantuk dan berbicara sendiri ketika proses pembelajaran. Dengan demikian minat belajar siswa akan berdampak apabila gurunya menggunakan model pembelajaran Auditory, Intellektualy, Repatition (AIR). Untuk lebih jelasnya Berikut hasil rekapitulasi tabel hasil wawancara

Tabel 2. Rekapitulasi Deskripsi Hasil Wawancara Siswa

\begin{tabular}{|c|c|c|c|}
\hline No & Pertanyaan & Jawaban & Kesimpulan \\
\hline 1. & $\begin{array}{l}\text { Bagaimana rasanya pembelajaran } \\
\text { menggunakan metode cermah \& } \\
\text { model pembelajaran Auditory, } \\
\text { Intellektualy, Repatition (AIR) }\end{array}$ & $\begin{array}{l}\text { Lebih menarik } \\
\text { dibelajarkan guru } \\
\text { menggunakan model } \\
\text { pembelajaran } \\
\text { Auditory, } \\
\text { Intellektualy, } \\
\text { Repatition }(A I R)\end{array}$ & $\begin{array}{lr}\text { Ada dampak } & \text { dan } \\
\text { perubahan } & \text { minat } \\
\text { belajar siswa ketika } \\
\text { menggunakan model } \\
\text { Auditory, Intellektualy, } \\
\text { Repatition (AIR) }\end{array}$ \\
\hline 2. & $\begin{array}{l}\text { Lebih minat belajar IPA dengan } \\
\text { menggunakan metode ceramah atau } \\
\text { model pembelajaran Auditory, } \\
\text { Intellektualy, Repatition (AIR) }\end{array}$ & $\begin{array}{l}\text { Lebih minat belajar } \\
\text { dengan menggunakan } \\
\text { model }(A I R) \text {. }\end{array}$ & $\begin{array}{l}\text { Ada dampak perubahan } \\
\text { minat belajar siswa } \\
\text { ketika menggunakan } \\
\text { model }(A I R) \text {. }\end{array}$ \\
\hline
\end{tabular}

Kondisi Awal

Kondisi awal berdasarkan pengamatan penelitian pada Hari Senin,
6 November 2017 dalam pembelajaran kelas III mapel IPA SDN Banjaran 02 terllihat peserta didik mengalami 
kejenuhan pada saat menerima materi yang diajarkan oleh guru. Pada kondisi awal guru melakukan kegiatan belajar mengajar menggunakan metode ceramah. Hal ini membuat siswa terlihat kurang antusis karena dengan penggunaan metode ceramah guru hanya menyampaikan materi saja ke peserta didik. Prosesnya hanya transfer ilmu dari guru ke peserta didik tanpa diselingi variasi pembelajaran apapun, kemudian dari pada itu kondisi kelas terdapat beberapa siswa yang mengantuk, beberapa siswa yang berbicara sendiri saat pembelajaran serta terdapat pula beberapa siswa yang ketika ditanya guru saat pembelajaran terkait materi pelajaran justru malah diam saja dan tidak mengerti menjawab.

Hal ini menegaskan bahwa metode pembelajaran ceramah ini kurang efektif digunakan guru saat mendesain pembelajaran karena mayoritas peserta didik ketika menerima materi saat pembelajaran menggunakan metode pembelajaran ceramah terlihat kurang minat belajar nya.

\section{Kondisi Proses}

Kondisi proses berdasarkan hasil pengamatan pada penelitian Hari Kamis, 9 November 2017 dalam pembelajaran kelas III mapel IPA SDN Banjaran 02 terlihat peserta didik sudah menunjukan dampak perubahan dari kondisi awal. Jika pada kondisi awal peserta didik diberikan pembelajaran IPA menggunakan metode ceramah saat pada kondisi proses, proses berlangsungya pembelajaran terlihat sudah berbeda yakni guru menggunakan model pembelajaran Auditory, Intellektualy, Repatition (AIR). Hal ini sebagai langkah maju serta variasi inovatif yang digunakan guru dalam memperbaiki kekurangan pada kondisi awal.

Pada kondisi proses terlihat yang awalnya peserta didik kurang antusias dalam menerima pembelajaran saat guru menggunakan model pembelajaran Auditory, Intellektualy, Repatition (AIR) siswa sudah terlihat senang dan antusias dalam menerima pembelajaran. Selain itu dampak perubahan peserta didik siswa kelas III SDN Banjaran 02 pada saat diterapkan guru menggunakan model pembelajaran Auditory, Intellektualy, Repatition (AIR) siswa 
terlihat lebih siap dalam menghadapi dan menerima pelajaran hal ini tentu sangat berbeda sekali pada saat kondisi awal yang dimana peserta didik terlihat ada yang mengantuk maupun berbicara sendiri saat pembelajaran berlangsung. Karena pada dasarmya model pembelajaran Auditory, Intellektualy, Repatition (AIR) menuntut siswa untuk dapat berpikir kritis, berpikir dalam berkonsep dan pengulangan belajar.

Hal itu berdampak pada respon siswa yang lebih responisf serta tidak mengantuk karena siswa diarahkan untuk terus berpikir sehingga jadi penanaman proses berpikir kritis, lalu siswa juga diarahkan guru dan dikenalkan bagaimana berpikir dalam berkonsep prosesnya adalah setelah pembelajaran siswa diarahkan berpikir untuk mengkonsep materi yang telah diajarkan. Untuk lebih jelas terdapat tabel rekapitulasi observasi atau pengamatan.

Tabel 3. Rekapitulasi Pengamatan Observasi Saat Guru Sebelum dan Sesudah Menggunakan Model Pembelajaran Auditory, Intellektualy, Repatition (AIR)

\begin{tabular}{|c|l|l|l|}
\hline No & \multicolumn{1}{|c|}{ Kondisi Awal } & \multicolumn{1}{|c|}{ Kondisi Proses } & \multicolumn{1}{|c|}{$\begin{array}{c}\text { Dampak/ } \\
\text { Perubahan }\end{array}$} \\
\hline 1. & $\begin{array}{l}\text { Siswa kurang antusias saat } \\
\text { menerima pelajaran }\end{array}$ & $\begin{array}{l}\text { Siswa sudah terlihat } \\
\text { antusias saat menerima } \\
\text { pelajaran }\end{array}$ & $\begin{array}{l}\text { Sudah ada } \\
\text { dampak }\end{array}$ \\
\hline 2. & $\begin{array}{l}\text { Siswa mengantuk saat } \\
\text { menerima pelajaran }\end{array}$ & $\begin{array}{l}\text { Siswa sudah tidak } \\
\text { mengantuk dan siap } \\
\text { menerima pelajaran }\end{array}$ & $\begin{array}{l}\text { Sudah ada } \\
\text { dampak }\end{array}$ \\
\hline 3. & $\begin{array}{l}\text { Siswa berbicara sendiri } \\
\text { saat pembelajaran }\end{array}$ & $\begin{array}{l}\text { Siswa sudah mulai aktif } \\
\text { saat pembelajaran }\end{array}$ & $\begin{array}{l}\text { Sudah ada } \\
\text { dampak }\end{array}$ \\
\hline
\end{tabular}

\section{SIMPULAN}

Dapat ditarik kesimpulan bahwa pembelajaran menggunakan model Auditory, Intellektualy, Repatition (AIR) dapat memberikan dampak dan perubahan terhadap minat belajar IPA siswa kelas III SDN 02 Banjaran semester I SDN 02 Banjaran. Karena dengan guru menggunakan model pembelajaran Auditory, Intellektualy, Repatition (AIR) siswa mengalami dampak perubahan diantaranya lebih 
antusias dan aktif dalam menerima materi pelajaran serta tidak mengantuk serta siap dalam menerima dan menghadapi pelajaran IPA materi cuaca dan pengaruhnya.

\section{DAFTAR PUSTAKA}

Afandi, M., Chamalah, E danWardani, O.P. (2013). Model dan Metode Pembelajaran di Sekolah. Semarang: Unissula Press.

Arikunto, S., dkk. 2008. Penelitian Tindakan Kelas. Jakarta: PT. Bumi Aksara.

Hamdani. 2011. Strategi Belajar Mengajar. Bandung: CV Pustaka Setia.

Johnson, E. 2009. Contextual Teaching and Learning: Menjadikan Kegiatan Belajar Mengajar Mengasyikan dan Bermakna. Bandung: Kaifa.

Rositawaty, S. (2008). Senang belajar Ilmu Pengetahuan Alam 3 SD. Jakarta: Pusat Perbukuan.

Shoimin. (2014). Model Pembelajaran Inovatif dalam Kurikulum 2013. Yogyakarta: Ar-Ruzza Media.

Susanto, A. (2013). Teori Belajar dan Pembelajaran di Sekolah Dasar. Jakarta: Kencana.

Trianto.(2010). Model Pembelajaran Terpadu. Jakarta: PT. Bumi Aksara. 